\title{
POLLEN-FRUIT SYNDROMES: A CASE WITH BIRCH-APPLE-CARROT ASSOCIATION
}

\author{
Minov, J., J. Karadzinska-Bislimovska, S. Stoleski, \\ D. Mijakoski, M. Marsenic, S. Risteska-Kuc and S. Milkovska
}

Institute of Occupational Health-WHO Collaborating Center, Skopje, R. Macedonia, Europe

Received 2014-04-22; Revised 2014-05-05; Accepted 2014-05-10

\begin{abstract}
Subjects with sensitivities to certain pollen can experience oral or systemic allergic symptoms associated with ingestion of various fruits, vegetables and nuts. In this case report a birch-apple-carrot association in 23-year-old man suffering from pollinosis who experienced few episodes of oral allergy syndrome, generalized urticaria and bronchospasm immediately time after ingestion of fresh and cooked apple and carrot is presented. Skin Prick Tests (SPT) to standard inhalant and food allergens were positive for birch, lime, apple and carrot. SPT for apricot was also positive, despite the patient did not experienced any allergic symptom after consumption of fresh or cooked apricot. This case report represents the description of an IgE-mediated systemic allergic reaction to both apple and carrot in both fresh and cooked form which is not usual reaction in the patients with birch-food association.
\end{abstract}

Keywords: Apple, Birch, Carrot, Cross-Reactivity, Food Allergy

\section{INTRODUCTION}

Subjects suffering from pollinosis often display adverse reactions after the ingestion of a wide variety of plant-derived foods as a consequence of Immunoglobulin $\mathrm{E}$ (IgE) cross-reactive structures shared by pollen and food allergen sources. Since as far back as 1948, it has been recognized that people sensitized to certain pollen also experienced oral symptoms such as itching and burning of the mouth associated with ingestion of certain foods (i.e., various fruits, vegetables and nuts) (Kelso, 2000). Studies conducted in the early 1980's found common epitopes between birch pollen and certain foods, confirming the association between birch pollenosis and sensitivity to a wide variety of fruits and vegetables (Calkhoven et al., 1987).

The term Oral Allergy Syndrome (OAS) has been established in 1987 to describe the phenomenon of oral or systemic symptoms associated with the intake of fruits, vegetables, nuts or all three, in a person with pollen sensitivity (Amlot et al., 1987). Some controversy exists regarding this term because some authors use it to Corresponding Author: Minov, J., Institute of Occupational Health-WHO Collaborating Center, Skopje, R. Macedonia, Europe

describe the association between inhalant pollenosis and food sensitivity, whereas others use the term to describe oral symptoms caused by any food allergen unrelated to pollen sensitivity. Because of this discrepancy food sensitivity associated with pollen is often termed pollenfood allergy syndrome (Ma et al., 2003).

The prevalence of food allergy in general population is estimated to be $2-4 \%$, up to $4.3 \%$ for fruits and $1.4 \%$ to vegetables (Zuidmeer et al., 2008). Sensitivity to allergens from apple (Malus domesticus) and carrot (Daucus carota) is found to be very frequent in food allergic subjects (Burney et al., 2010). As genetic and environmental factors may impact the qualitative and quantitative composition of these foods with regard to their allergens and iso-allergens, sensitization and clinical reactivity depend on geographical region (Fernandez-Rivas et al., 2006).

It is established that Bet $v 1$, the major allergen of birch (Betula), has homologs in Rosacea fruits, like apricot (Pru ar 1), peach (Pru p 1), apple (Mal d 1), pear $(P y r \quad c 1)$ and cherry (Pru av 1), which all may contribute to the clinical manifestations of the birch- 
fruit syndrome (Breiteneder and Ebner, 2000). Bet $v 1$ homologs are also present in Apicaceae vegetables, like celery (Api g l) and carrot (Dau c 1) and birchcarrot and birch-celery syndromes have been described (Ballmer-Weber et al., 2001; Egger et al., 2006). The Rosacea fruits allergens may also crossreact with mugwort allergens, being involved in the mugwort-peach association that especially occurs in the Mediteranean area (Lombardero et al., 2004).

The aim of this case report is to present systemic allergic reaction following consumption of apple or carrot in a subject with seasonal allergic airway disease sensitized to birch pollen.

\section{MATERIALS AND METHODS}

The diagnostic work-up in this case included history taking, clinical examination, skin prick tests (SPTs) to common inhalant and food allergens, spirometry, histamine challenge test, hemogram, Electrocardiogram (ECG) and chest radiography.

\subsection{History}

The history was completed by questions for type, occurrence, duration and intensity of the patient's symptoms, treatment of the symptoms, personal history for allergic and other diseases, family history for allergic diseases, as well as for his habits.

\subsection{SPTs}

SPTs were performed on the volar part of the forearm using allergen extracts (Torlak, Serbia) of common inhalant allergens, i.e., birch (5,000 PNU), lime $(5,000$ PNU), grass mixed (Agrostis alba, Alopecurus pralensis, Dactylis glomerata, Festuca pranesis, Phleum pratense, Poa pratensis, Secale cereale, Triticum aestivum and Zea mais; 5,000 PNU), mugwort (5,000 PNU), plantain (5,000 PNU), Dermatophagoides pteronyssinus $(4,000$ PNU), fungi mixed (4,000 PNU), dog hair (4,000 PNU), cat fur (4,000 PNU) and feathers mixed (chicken and duck feathers; 4,000 PNU), as well as of food allergens, i.e. apple $(1: 20 \mathrm{w} / \mathrm{v})$, peach $(1: 20 \mathrm{w} / \mathrm{v})$, apricot $(1: 20$ $\mathrm{w} / \mathrm{v})$, strawberry $(1: 20 \mathrm{w} / \mathrm{v})$, cherry $(1: 20 \mathrm{w} / \mathrm{v})$ and carrot $(1: 20 \mathrm{w} / \mathrm{v})$, according to the actual recommendations (Dreborg and Frew, 1993). All tests included positive $\left(1 \mathrm{mg} \mathrm{mL} \mathrm{min}^{-1}\right.$ histamine) and negative $(0.9 \%$ saline) skin test controls. Prick tests were considered positive if the mean wheal diameter $20 \mathrm{~min}$ after allergen application was at least $3 \mathrm{~mm}$ larger than the size of the negative control. In addition, 8 atopic patients followed-up in our department were tested with the same food allergens as controls.

\subsection{Spirometry}

Spirometry, including measures of Forced Vital Capacity (FVC), Forced Expiratory Volume in one second $\left(\mathrm{FEV}_{1}\right), \mathrm{FEV}_{1} / \mathrm{FVC}$ ratio and Maximal Expiratory Flow at 50, 25 and $25-75 \%$ of FVC $\left(\mathrm{MEF}_{50}\right.$, $\mathrm{MEF}_{25}$ and $\mathrm{MEF}_{25-75}$, respectively), was performed in all subjects using spirometer Ganshorn SanoScope LF8 (Ganshorn Medizin Electronic GmbH, Germany) with recording the best result from three measurements the values of $\mathrm{FEV}_{1}$ of which were within $5 \%$ of each other. The results of spirometry were expressed as percentages of the predicted values according to the actual recommendations of European Repsiratory Society (ERS) and American Thoracic Society (ATS) (Miller et al., 2005; Clausen et al., 1997).

\subsection{Histamine Challenge}

Nonspecific Bronchial Responisiveness (BHR) was assessed by histamine challenge test performed according to the actual ERS/ATS recommendations (Sterk Sterk et al., 1993; ATS, 2000). Concentrations of $0.5,1,2,4$ and $8 \mathrm{mg} \mathrm{mL}^{-1}$ histamine (Torlak, Serbia) were prepared by dilution with buffered saline. The doses of aerosol generated by Pari LC nebulizer (Pari GmbH, Germany) with output rate $0.17 \mathrm{~mL} \min ^{-1}$ were inhaled by mouthpiece. The patient inhaled increasing concentrations of histamine using a tidal breathing method until $\mathrm{FEV}_{1}$ fell by more than $20 \%$ of its base value (provocative concentration $20-\mathrm{PC}_{20}$ ) or the highest concentration was reached. The test was considered positive if $\mathrm{PC}_{20}$ was equal or less than $4 \mathrm{mg} \mathrm{mL}^{-1}$. According to the ATS recommendations, $\mathrm{BHR}$ was categorized as moderate to severe BHR $\left(\mathrm{PC}_{20}<1.0 \mathrm{mg} \mathrm{mL}{ }^{-1}\right)$, mild BHR $\left(\mathrm{PC}_{20}=\right.$ 1.0-4.0 mg mL $\left.{ }^{-1}\right)$ and borderline $\mathrm{BHR}\left(\mathrm{PC}_{20}>4.0 \mathrm{mg}\right.$ $\mathrm{mL}^{-1}$ ) (ATS, 2000).

\subsection{Diagnostic Criteria for Hay Fever, Allergic Asthma, Pollinosis and Pollen-Fruit Syndrome}

The diagnosis of hay fever (seasonal allergic rhinitis) was based on the presence of sneezing, nasal itching, runny nose and/or blocked nose with or without ocular symptoms (red and itchy eyes) and positive SPTs to one or more pollen allergens.

According to the actual recommendations of the Global Initiative for Asthma (GINA), the diagnosis of asthma was based on symptoms such as episodic 
breathlessness, wheezing, cough and chest tightness; positive histamine challenge and positive SPTs to one or more common inhalant allergens (GINA, 2012).

Pollinosis is defined as the appearance of respiratory symptoms (rhinoconjunctivitis and/or asthma) as a result of the inhalation of pollen to which the individual is sensitized (Bartra et al., 2009).

The diagnosis of pollen-fruit syndrome was based on the presence of food sensitivity (i.e., occurrence of oral or systemic allergic symptoms after ingestion of some plant-derived food and positive SPTs to food allergens) in subject suffering from pollinosis (Ma et al., 2003; Bartra et al., 2009).

\section{RESULTS}

A 23-year-old male student, never smoker, for more than 10 years experienced rhinorrhea, nasal itching, sneezing, cough, dyspnea and wheezing in the period March-June. The doctors considered he had seasonal allergic rhinitis and he was treated as an outpatient with antihistamines and/or intranasal corticosteroids. His 57-year-old mother also suffered from seasonal allergic rhinitis.

Five years ago he experienced a severe episode of oral allergy syndrome (oral pruritus, swelling of lips, tongue and throat and hoarseness), generalized urticaria and bronchospasm, 20-30 min after eating cooked apple that required hospital admission and treatment with parenteral antihistamines, corticosteroids and teophylline. Later he had similar reactions immediately after ingestion of small amount of fresh apple, as well as cooked carrot. Severe reaction that required a hospital admission occurred immediately after eating of fresh carrot three years ago. Since then he avoided these foods.

He visited our department in November 2011. He had no symptoms, the findings from the clinical examination were normal and the values of the spirometric parameters were within the range of the predictive values. The findings from chest radiography, ECG and laboratory blood analysis were also normal.

Positive SPTs were obtained for birch pollen, lime pollen, apple and carrot. In addition, we registered positive SPT for apricot despite the patient did not experienced any allergic symptom after consumption of fresh or cooked apricot. The SPTs to the same food allergens in all controls were negative.

Despite the patient experienced dyspnea and wheezing in the period March-June for a period of time, up to this visit his bronchial reactivity was not assessed and he did not take asthma medications. The histamine challenge test was positive, with a significant decrease $(28 \%)$ in the $\mathrm{FEV}_{1}$ value as compared to its basal value $\left(\mathrm{PC}_{20}=2.73 \mathrm{mg} \mathrm{mL}^{-1}\right)$ indicating mild BHR.

Despite SPTs and serologic tests solely indicate the presence of allergen-specific IgE but do not diagnose the clinical appearance of food allergy and the Double-Blind Placebo-Controlled Food Challenge (DBPCFC) is considered still the only conclusive evidence of a food allergy (Lieberman and Sicherer, 2010), we did not performed an oral challenge with apple and carrot as the patient had severe reactions after eating this food.

At the end we concluded that the patient suffered from pollinosis (seasonal allergic rhinitis and asthma) accompanied by pollen-fruit syndrome. Treatment of the pollinosis was based on the actual recommendations (GINA, 2012). Regarding the consumption of apple and carrot, we recommended their avoidance in any form. In addition, we suggested avoidance of apricot, as the severe reaction after its ingestion cannot be excluded.

\section{DISCUSSION}

It is established that up to $70 \%$ of subjects allergic to birch pollen also suffer plant-food allergy (fundamentally Rosacea fruits, together with celery, carrot and hazelnut) (Bartra et al., 2009; Sénéchal et al., 1999; Sloane and Sheffer, 2001). The most common clinical manifestation comprises local oropharyngeal manifestations when fresh food is ingested; in comparison, the cooked food usually is well tolerated (Eriksson et al., 1982; Breitender and Mills, 2005). Results of several studies indicated that in this association the initial triggering factor is inhalatory sensitization to birch pollen (Vieths et al., 2002). In the literature many pollen-food associations are presented; e.g., birch association with apple, pear, peach, plum, cherry, carrot, almond and hazelnut; grasses association with tomato; ragweed association with melon, cucumber, kiwi and banana. Not every patient sensitized to pollen develops symptoms by cross-reacting fruits, vegetables or nuts. In addition, patients may react to a few, but not to all of the mentioned foods (Sloane and Sheffer, 2001).

This case report is a description of a few episodes of systemic allergic reactions after ingestion of fresh and cooked apple and carrot in a subject with seasonal respiratory symptoms sensitized to birch and lime pollen. Systemic allergic reactions after ingestion of fruits, vegetables or nuts are not usual in the subjects with birch pollinosis. In addition, such reactions are 
also not usual after ingestion of cooked fruits or vegetables (Bartra et al., 2009; Sloane and Sheffer, 2001). On the other side, there are pollen-food associations in which the clinical manifestations are usually systemic. For example, subjects with celerymugwort-spice syndrome develop systemic reactions (urticaria, angioedema, bronchospasm and even anaphylactic shock) after ingestion both raw and cooked vegetables. Furthermore, there is evidence that subjects with respiratory allergy to Platanus pollen suffer an increased frequency of plant-food allergy (apple, peach, hazelnut, walnut) with systemic reactions as the predominant manifestations (Miralles et al., 2002; Enrique et al., 2002). The possible explanation of development of systemic reactions in these associations is that the causal allergens are proteins resistant to cooking and gastric digestion (Egger et al., 2006).

As an avoidance of the foods causing allergic manifestations in patients with pollen-fruit syndromes is considered as the best way to prevent these reactions, our patient was advised to avoid incriminated foods in both fresh and cooked form. Besides the results of some studies indicate improvement of food allergy in the patients with Platanus-food syndrome treated with immunotherapy as compared to untreated patients (Alonso et al., 2007), the effect of this treatment should be confirmed in further studies.

Limitation of the present case report is that the food allergy was confirmed by positive SPTs to food allergens in the patient with birch pollinosis who developed symptoms after ingestion of certain foods and negative SPTs to the same allergens in the controls, not by positive DBPCFC that is considered as a gold standard for diagnosis of food allergy.

\section{CONCLUSION}

This case report represents the description of a systemic allergic reaction to both apple and carrot independently of their form (fresh or cooked) in the subject with seasonal respiratory symptoms due to sensitization to birch pollen. Although much has been discovered about pollen-food allergy syndrome since it was first recognized 70 years ago, further studies are necessary to further define the clinical features and the natural progression of the disease. Additionally, there is a need for improved diagnostic testing and treatment options in order to develop a more specific approach for the diagnosis and management of patients with pollen-food association.

\section{REFERENCES}

Alonso, R., E. Enrique, F. Pineda, M. Basagana and M.M. San Miguel-Moncin et al., 2007. An observational study on outgrowing food allergy during non-birch pollen-specific, subcutaneous immunotherapy. Arch Allergy Immunol., 143: 185189. PMID: 17284927

Amlot, P.L., D.M. Kemeny, C. Zachary, P. Parkes and M.H. Lessof, 1987. Oral Allergy Syndrome (OAS): Symptoms of IgE-mediated hypersensitivity to foods. Clin. Allergy, 17: 33-42. DOI: 10.1111/j.1365-2222.1987.tb02317.x

ATS, 2000. Guidelines for metacholine and exercise challenge testing -1999. Am. Respir. Crit. Care Med., 161: 309-329. DOI: 10.1164/ajrccm.161.1.ats11-99

Ballmer-Weber, B.K., B. Wuthrich, A. Wangorsch, K. Fotisch and F. Altmann et al., 2001. Carrot allergy: Double blinded, placebo-controlled food challenge and identification of allergens. J. Allergy Clin. Immunol., 108: 301-307. DOI: 10.1067/mai.2001.116430

Bartra, J., J. Sastre, A. del Cuvillo, J. Montoro and I. Jauregui et al., 2009. From pollinosis to digestive allergy. J. Invest. Allergol. Clin. Immunol., 19: 3-10. DOI: $10.1186 / 2045-7022-3-S 3-P 31$

Breitender, H. and E. Mills, 2005. Plant food allergens structural and functional aspects of allergenicity. Biotech. Adv., 23: 395-399. DOI: 10.1016/j.biotechadv.2005.05.004

Breiteneder, H. and C. Ebner, 2000. Molecular and biochemical classification of plant-derived food allergens. J. Allergy Clin. Immunol., 106: 27-36. DOI: $10.1067 /$ mai.2000.106929

Burney, P., C. Summers, C. Chinn, R. Hooper and R. van Ree et al., 2010. Prevalence and distribution of sensitization to foods in European community respiratory health survey: A EuroPrevall analysis. Allergy, 65: 1182-1188. PMID: 20180791

Calkhoven, P.G., M. Aalbers, V.L. Koshte, O. Pos and H.D. Oei et al., 1987. Cross-reactivity among birch pollen, vegetables and fruits as detected by $\operatorname{IgE}$ antibodies is due to at least three distinct crossreactive structures. Allergy, 4: 382-390. DOI: 10.1111/j.1398-9995.1987.tb02225.x

Clausen, J.L., A.L. Coates and P.H. Quanjer, 1997. Measurement of lung volumes in humans: Review and recommendations from an ATS/ERS workshop. Eur. Respir. J., 10: 1205-1206. DOI: 10.1183/09031936.97.10061205 
Dreborg, S. and A. Frew, 1993. Position paper: Allergen standardization and skin tests. The European academy of allergology and clinical immunology. Allergy, 48: 48-82. DOI: 10.1111/j.13989995.1993.tb04756.x

Egger, M., S. Mutschlechner, N. Wopfner, G. Gadermaier and P. Briza et al., 2006. Pollen-food syndromes associated with weed pollinosis: An update from the molecular point of view. Allergy, 61: 461-476. DOI: $10.1111 / \mathrm{j} .1398-$ 9995.2006.00994.x

Enrique, E., A. Cistero-Bahima, B. Bartolome, R. Alonso and M.M. San Miguel-Moncin et al., 2002. Platanus acerifolia pollinosis and food allergy. Allergy, 57: 351-356. DOI: 10.1034/j.13989995.2002.1s3509.x

Eriksson, N.E., H. Formgren and E. Svenonius, 1982. Food hypersensitivity in patients with pollen allergy. Allergy, 37: 437-443. DOI: 10.1111/j.13989995.1982.tb02323.x

Fernandez-Rivas, M., S. Bolhaar, E. Gonzalez-Mancebo, R. Asero and A. Van Leeuwen et al., 2006. Apple allergy across Europe: How allergen sensitization profiles determine the clinical expression of allergies to plant foods. J. Allergy Clin. Immunol., 118: 481-488. DOI: 10.1016/j.jaci.2006.05.012

GINA, 2012. Global strategy for asthma management and prevention. Global Initiative for Asthma.

Kelso, J.M., 2000. Pollen-food allergy syndrome. Clin. Exp. Allergy, 30: 905-907. DOI: 10.1046/j.13652222.2000.00872.x

Lieberman, J.A. and S.H. Sicherer, 2010. The diagnosis of food allergy. Am. J. Rhinol. Allergy, 24: 439-443.

Lombardero, M., F.J. Garcia-Selles, F. Polo, L. Jimeno and M.J. Chamoro et al., 2004. Prevalence of sensitization to Artemisia allergens Art v 1, Art v 3 and Art v $60 \mathrm{kDa}$. Cross-reactivity among Art v 3 and other relevant lipid-transfer protein allergens. Clin. Exp. Allergy, 34: 1415-1421. DOI: 10.1111/j.1365-2222.2004.02053.x
Ma, S., S.H. Sicherer and A. Nowak-Wegrzyn, 2003. A survey on the management of pollen-food allergy syndrome in allergy practices. J. Allergy Clin. Immunol., 112: 784-788. DOI: 10.1016/S00916749(03)02008-6

Miller, M.R., J. Hankison, V. Brusasco, F. Burgos and R. Casaburi et al., 2005. Standardization of spirometry. Eur. Respir. J. 26: 319-338. DOI: 10.1183/09031936.05.00034805

Miralles, J.C., F. Caravaca, F. Guillen, M. Lombardeo and J.M. Negro, 2002. Cross-reactivity between platanus pollen and vegetables. Allergy, 57: 146149. DOI: 10.1034/j.1398-9995.2002.1s3407.x

Sénéchal, H., S. Geny, F.X. Desvaux, M. Busson and C. Mayer et al., 1999. Genetics and specific immune response in allergy to birch pollen and food: Evidence of a strong, positive association between atopy and the HLA class II allele HLA-DR7. J. Allergy Clin. Immunol., 104: 395-401. DOI: 10.1016/S0091-6749(99)70384-2

Sloane, D. and A. Sheffer, 2001. Oral allergy syndrome. Allergy Asthma Proc., 22: 321-325. PMID: 11715223

Sterk, P.J., L.M. Fabbri, P.H. Quanjer, D.W. Cockcroft and P.M. O'Byrne, et al., 1993. Airway responsiveness. Standardized challenge testing with pharmacological, physical and sensitizing stimuli in adults. Report Working Party Standardization of Lung Function Tests, European Community for Steel and Coal. Official Statement of the European Respiratory Society. Eur. Respir. J. Suppl., 16: 5383. PMID: 8499055

Vieths, S., S. Scheurer and B. Ballmer-Weber, 2002. Current understanding of cross-reactivity of food allergens and pollen. Ann NY Acad Sci 2002; 964: 47-68. DOI: 10.1111/j.1749-6632.2002.tb04132.x

Zuidmeer, L., K. Goldhahn, R.J. Rona, D. Gislason and C. Madsen et al., 2008. The prevalence of plant food allergies: A systematic review. J. Allergy Clin. Immunol., 121: 1210-1218. DOI: 10.1016/j.jaci.2008.02.019 